\title{
Margem dentro da margem: olhar angolano para o Brasil
}

\author{
Alexandre Montaury \\ (Pontifícia Universidade Católica do Rio de Janeiro)
}

\begin{abstract}
RESUMO: O ARTIGO PROPÕE UMA ANÁLISE DE UM DOS MAIS RECENTES TRABALHOS DO ESCRITOR RUY DUARTE DE CARVALHO, DESMEDIDA - LUANDA, SÃO PAULO, SÃO FRANCISCO E VOLTA: CRÓNICAS DO BRASIL (2006), PARA FORMULAR ENTENDIMENTOS ACERCA DO REDIMENSIONAMENTO DOS TRÂNSITOS CULTURAIS ENTRE O BRASIL E ANGOLA, NA EXPERIÊNCIA CONTEMPORÂNEA. O OBJETIVO DESTA PROPOSTA É PÔR EM QUESTÃO A ESPECIFICIDADE DE UM OLHAR ANGOLANO PARA O BRASIL QUE, ALÉM DE LER A MARGEM DE DENTRO DA MARGEM, ATUALIZA AS FORMAS DE "COMUNHÃO DA EXPERIÊNCIA HISTÓRICA" E AS CATEGORIAS MODERNAS COLONIAIS LIGADAS ÀS COMUNIDADES DE LÍNGUA PORTUGUESA.
\end{abstract}

ABSTRACT: THE ARTICLE AIMS AT ANALYZING ONE OF THE MOST RECENT WORKS WRITTEN BY RUY DUARTE DE CARVALHO, DESMEDIDA - LUANDA, SÃO PAULO, SÃO FRANCISCO E VOLTA: CRÓNICAS DO BRASIL (2006), IN ORDER TO FORMULATE UNDERSTANDINGS ABOUT THE NEW DIMENSIONS OF THE CULTURAL EXCHANGES BETWEEN BRAZIL AND ANGOLA, IN THE CONTEMPORARY EXPERIENCE. THE OBJECTIVE HERE IS TO QUESTION THE SPECIFICITY OF AN ANGOLAN LOOK INTO A BRAZIL THAT, APART FROM READING THE MARGIN FROM WITHIN THE MARGIN, UPDATES THE FORMS OF "COMMUNION OF THE HISTORICAL EXPERIENCE" AND THE MODERN COLONIAL CATEGORIES CONNECTED TO THE COMMUNITIES OF PORTUGUESE LANGUAGE.

PALAVRAS-CHAVE: LITERATURAS DE LÍNGUA PORTUGUESA - RUY DUARTE DE CARVALHO - NARRATIVA DE VIAGEM - PÓS-COLONIALISMO.

KEY-WORDS: PORTUGUESE LANGUAGE LITERATURES - RUY DUARTE DE CARVALHO - TRAVEL NARRATIVE - POST-COLONIALISM. 
m 1986, Helena Riaúzova abriu o seu "Ensaio sobre a moderna literatura angolana (1975-1985)" destacando a originalidade desta literatura no universo da língua portuguesa. Para a autora, esta afirmação se baseia em duas circunstâncias decisivas. Em primeiro lugar, a intensa atividade de escrita mantida por uma geração de escritores e intelectuais durante o período da luta contra o colonialismo; em segundo lugar, a revolução portuguesa de 1974, que criou, em Angola, as condições fundamentais para a emergência de uma reflexão coletiva voltada para o passado colonial, para a luta pela independência e para a construção de uma sociedade nova.

A moderna literatura angolana surgia, em grande parte, graças à sobrevivência, em condições adversas, de textos produzidos nas celas das prisões, nos campos de concentração e nos campos de guerrilha. Para Riaúzova, a reconstrução nacional exigia novas negociações simbólicas e identitárias que pressupunham uma coexistência estreita e uma "ação recíproca" entre as literaturas de língua portuguesa. Segundo a autora,

A ocorrência de traços específicos comuns, de alguns pontos estáveis nos sistemas das literaturas de língua portuguesa é produto não apenas do uso de uma mesma língua, mas também, e principalmente, da comunhão de experiências históricas. (RIAÚZOVA, 1986: 24)

Pretendo focalizar esta forma de "comunhão de experiência histórica", buscando redimensioná-la na experiência contemporânea. Neste sentido, é importante marcar que o objeto central da análise que proponho, o texto Desmedida, de Ruy Duarte de Carvalho, surge em 2006, para, de certa forma, confirmar o argumento que, precisamente vinte anos antes, abria a publicação de Helena Riaúzova.

A análise que proponho se insere, entretanto, numa pesquisa mais ampla, voltada para o estudo das representações pós-coloniais nas literaturas contemporâneas de língua portuguesa, desenvolvida no âmbito do Programa de Pós-graduação em Letras da PUC-Rio. De forma mais geral, o projeto visa interrogar a forma com que a experiência colonial portuguesa está registrada na tradição literária, tendo alcançado sua máxima expressão em textos do século XX, no momento em que escritores e intelectuais, a partir de diferentes focalizações, buscavam colocar em cena parte do 
legado que recaía sobre aquelas sociedades após treze anos (1961-1974) de guerras coloniais.

A partir das últimas décadas do século XX, foram formulados argumentos e proposições acerca das condições pós-coloniais no mundo globalizado, evidenciando a estreita articulação que existiu entre a modernidade ocidental, dos séculos XIX e XX, e o projeto colonial europeu. Esses novos argumentos abriram espaço para novas formas de produção de conhecimento e de auto-representação, tanto dos povos colonizados quanto dos colonizadores. Afinal, as condições pós-coloniais afetaram diretamente as práticas simbólicas levadas a efeito nos países centrais europeus e nas sociedades periféricas de um modo geral, deflagrando em suas produções literárias e culturais uma grande diversificação.

Uma vertente desse movimento de reconfiguração conceitual do colonialismo privilegiou a experiência inglesa, como a de um colonialismo/pós-colonialismo hegemônico, sobre o qual uma extensa gama de textos surgiu para testemunhar, representar, alegorizar e problematizar, na ficção e na historiografia, o convívio entre alteridades e diferenças que, no processo, eram remodeladas ou re-encenadas como centro ou como margem.

Partindo da premissa de que, desde a década de 50, está em curso, nos países de expressão portuguesa, um ajuste de contas de natureza política e simbólica associado claramente à experiência colonial, interessa-me pensar o impacto destas objetivações na produção literária contemporânea. Para isto, tomo, como objeto preliminar de estudo, o texto Desmedida - Luanda, São Paulo, São Francisco e volta: crónicas do Brasil, um dos mais recentes trabalhos do escritor luso-angolano Ruy Duarte de Carvalho.

O que move a análise que proponho é o fato de que há, no texto do autor, questões decisivas no contexto das renegociações identitárias no mundo lusófono e, particularmente, na constituição simbólica de uma identificação angolana. Nas suas crônicas, Ruy Duarte de Carvalho convoca o leitor para uma viagem pelas digressões de um intelectual proveniente do hemisfério sul, com todas as especificidades que isto implica, deslocando-se pelo centro do Brasil ao mesmo tempo em que percorre instruções prévias sobre o país, indo da fluente intimidade com Guimarães Rosa e Euclides da Cunha a comentários sobre o processo de independência do Brasil: 
É, os portugueses fugiram todos, os brasileiros ganharam a batalha, e só não entraram logo em Salvador porque o brigadeiro do imperador achou que deviam esperar por representantes do Rio de Janeiro. O general português acabou por render-se, e no dia combinado para os brasileiros tomarem posse deixou o palácio antes deles lá chegarem e meteu-se num barco, ao largo, coisa muito parecida com o que se passou aqui em Luanda com a gente, do dia 10 para o dia 11 de novembro de 1975, data da nossa independência nacional. (CARVALHO, 2006: 197)

A consciência de um olhar relativamente inaugural para o Brasil marca a viagem exploratória empreendida pelo narrador e parece abrir a hipótese de que o Brasil havia sido até agora, e desde o início da expansão européia, terreno privilegiado para observadores e exploradores europeus, ou originários do hemisfério norte. A produção de uma mentalidade global européia, a partir de explorações científicas destinadas a dar sentido à terra ou a garantir a vanguarda do progresso, deu forma a uma imagem alegorizada, tipificada em clichês brasileiros. A novidade dessas crônicas reside, em grande parte, na relativização da mediação européia no entendimento do Brasil. Afinal, como argumenta o narrador do texto, o Brasil não se deu tanto a ver àqueles que vinham, como ele, de outro ponto do hemisfério sul, com a especificidade geral que isso comporta imediatamente.

Sendo Angola uma referência fundamental do Brasil, e vice-versa, não é difícil contemplar singularidades evidentes por implicações comuns e identificar continuidades e contigüidades entre o Brasil, Angola e Portugal, por inerência. Este traço remeteria para o conceito de "comunhão de experiência histórica”, de Helena Riaúzova. É aí que parece iniciar o processo de escrita de Ruy Duarte de Carvalho. A identificação de

tudo o que há de complementaridades, de contigüidades e de simultaneidades entre o Brasil e Angola, desde a era das descobertas até à dos banditismos sociais que entram muito pelo século XX. (CARVALHO, 2006: 43)

Neste sentido, uma "ação recíproca” entre as literaturas de língua portuguesa é a condição fundamental para o projeto do autor. Se a perspectiva portuguesa pudesse ser tomada como uma nova emergência, agora demarcada da 
ficção imperial sustentada ao longo dos últimos séculos como "um espectro no imaginário português moderno" (LOURENÇO, 2007: 29), seria possível retomar também as proposições de Boaventura de Sousa Santos:

É fundamental que (os portugueses) nos desfamiliarizemos do Norte imperial e que aprendamos com o Sul. Mas advirto que o Sul é, ele próprio, um produto do império e, por isso, a aprendizagem com o Sul exige igualmente a desfamiliarização em relação ao Sul imperial, ou seja, em relação a tudo o que no Sul é o resultado da relação colonial capitalista (SANTOS, 1996: 33).

Uma das preocupações do sociólogo português reside na investigação de uma deslocalização do que chama de Norte imperial. Sua proposta é a de substituir uma visão pós-colonial hegemônica, ligada ao que classifica como o pós-modernismo celebratório que olha a margem desde o centro, para priorizar o pós-colonialismo de oposição que, no interior da margem, buscaria redefinir:

quem somos nós [os portugueses] neste espaço de língua oficial portuguesa, nas nossas diferenças e cumplicidades integradas num mundo crescentemente globalizado, segundo uma lógica em cujos desenhos temos, quando muito, uma participação subordinada, uma lógica que ou trivializa ou, pelo contrário, dramatiza as nossas diferenças, mas em qualquer caso, bloqueia a construção das cumplicidades. (SANTOS, 1996: 46)

Neste sentido, em um movimento que busca a construção de cumplicidades, Ruy Duarte de Carvalho, mais do que privilegiar o "confronto de uma língua que se interroga acerca de sua capacidade para entrar em uma paisagem e dizer dela no que se escreve", evoca uma "literatura de fronteira" como método e busca vincular-se fundamentalmente ao fato de uma expressão literária ser capaz de colocar em causa o domínio de expressões localizadas nessa mesma língua:

Fronteira, pois, como orla de alcance - por parte de uma expressão local (cultura), dentro de uma dada escrita - das expressões literárias dentro de uma língua e da história da sua escrita... todas as expressões literárias locais se constituiriam assim como literaturas de fronteira em que a paisagem seria a língua maior, e aí, 
uma vez realizadas, se transmudariam em voz... poderia talvez mesmo encararse a ousadia de entender como literatura de fronteira toda a escrita que pela sua maneira de dizer as coisas, virando fala que passa a ser voz, perturbe o poder que a língua também é. (CARVALHO, 2005: 12)

Em Desmedida, a expedição principia, na verdade, no Norte imperial, especialmente em Paris, com o desenho de um plano que inclui idas e vindas entre as duas margens do Atlântico. Nas palavras do narrador, há "muito Brasil para explicar e uma Angola para entender", o que leva o leitor a percorrer alguns fragmentos da história de dois países que dividiram condições históricas semelhantes em épocas distintas de sua existência. O leitor não está diante de uma peregrinação nem do relato que dela resultou, como nos informa o narrador:

Um livro a insinuar-se? E por que não? Um livro mais de "viagem", mas que também não fosse um desses registros paraliterários de errâncias e de evasões a puxar para o sério e para a auto-ajuda. Que remetesse para os domínios em que me movo mas admitisse derivas. [...] Ensaiasse tão-só, talvez, dizer do Brasil a partir de Angola, a partir da situação nacional que é a minha em relação ao mundo e a Angola. (CARVALHO, 2006: 42)

Mergulhado em um conjunto de objetivações que, pouco a pouco, dão forma a uma comunidade de traços particulares e geram sensação de pertencimento ou de afinidade, o narrador se mobiliza em refazer os trajetos de Saint-Hilaire, Richard Burton, Theodoro Sampaio e Blaise Cendrars no Brasil e, a partir da pavimentação desses percursos anteriores, em encontros e desencontros, se volta para os sertões de Guimarães Rosa e de Euclides da Cunha.

O vale do rio São Francisco é a origem e o destino da viagem, onde o narrador do texto lê e relê a sua experiência empírica mediada pela memória da cultura lusófona. Na perspectiva do narrador, o São Francisco é um dos eixos identitários brasileiros, tomado a partir de sua relevância para uma idéia específica do Brasil, encenada a partir da influência de um "rio incontestável", nas palavras de Guimarães Rosa (ROSA, 1985: 34). A imagem de um rio mítico que já foi cenário de expedições de desbravamento, afluente da exploração mineira e, mais recentemente, da migração das populações nordestinas para São Paulo, 
articula-se ainda a um dos temas da atualidade: a possibilidade de transposição de suas águas para a irrigação do Nordeste. Tomado por uma razão metonímica, que tomará a parte pelo todo, o narrador assume o projeto de escrever o Brasil ao percorrer o trajeto de Minas a Pernambuco na companhia de Rosa e Euclides da Cunha. Nas suas palavras, "Só João Cabral me ficaria de fora, mas terei os canaviais do baixo São Francisco" (CARVALHO, 2006: 42).

Um dos eixos centrais do texto, anunciado de partida, é a proposta de refazer, numa viagem, o trajeto de Guimarães Rosa pelos sertões do São Francisco:

Tem um ponto no mapa do Brasil, tem um vértice que é onde os estados de Goiás, de Minas Gerais e da Bahia se encontram e o Distrito Federal é o mesmo ao lado. Aí sim, gostaria de ir... é lá que se passa muita da ação do Grande Sertão Veredas... e depois descer para o alto do São Francisco, que é o resto das paisagens de Guimarães Rosa... e ao baixo São Francisco, podendo, ia também... porque encosta aos Sertões euclidianos... sou estrangeiro aqui e nada me impede de incorrer no anacronismo de querer ir ver, de perto, Guimarães Rosa e Euclides da Cunha... (CARVALHO, 2006: 15)

A partir de uma aguda observação do pormenor, o narrador reconstitui, numa forma particular de articulação entre arte literária e saber antropológico, percursos de Guimarães Rosa pelo São Francisco. No texto, o autor explora pequenas histórias locais e enredos alheios, instalando-os em sua engrenagem narrativa que costura percepções fugidias que, em geral, partem do que o narrador vê, lê ou se lembra de ter lido.

Pela seqüência de acasos e de associações que o texto organiza desde o início como um dispositivo narrativo, o leitor é absorvido por um projeto que viabiliza o livro a partir da convocação de explorações anteriores ao Brasil. O primeiro viajante evocado é Blaise Cendrars, poeta suíço que freqüentou o ambiente do modernismo paulista na década de 20, estabelecendo uma identificação entre o estrangeiro em viagem pelo interior do Brasil e aqueles que, como forasteiros, também constituíram o Brasil, de dentro e de fora, a partir de viagens anteriores.

Ao descer o rio São Francisco acompanhado por outras viagens a esse mesmo interior - como a de Richard Burton, precursor da antropologia no século XX, a de Auguste Saint-Hilaire, ou a de Theodoro Sampaio - a investigação do narrador passa a incorporar questões sobre a relação do Brasil 
com o vasto imaginário a que está associado, percorrendo inevitavelmente aspectos ligados ao confronto entre o litoral e o interior e a modernização do país. A articulação de uma idéia mítica de Brasil à narrativa principal se torna inevitável a ponto de uma figura típica do folclore brasileiro, como o saci-pererê, surgir em socorro do narrador para fazer avançar a sua narrativa:

[...] o saci-pererê da lenda nacional. Vem dar encontro com Cendrars aqui, que andou na guerra e tem um braço só. Vem dizer-lhe que não ligue para esse jornalista que anda a chamar-lhe Cendrars Sans Bras, nem para as autoridades alfandegárias e a polícia de fronteiras que por duas vezes já, uma em Santos e a outra no Rio de Janeiro, lhe dificultaram a entrada por ele não ter senão um braço e querer ainda assim desembarcar no Brasil numa altura em que a propaganda do governo anda a martelar, pela imprensa, que o país precisa é de braços. (CARVALHO, 2006: 36-37)

A desmontagem progressiva de mitos - como o da cordialidade - surge para articular, ao longo da narrativa, o pensamento do narrador a auto-ficções que fazem lembrar, simultaneamente, a escrita diarística e a narrativa de viagem. O texto de Ruy Duarte de Carvalho, situado entre a ficção e a reportagem, segue as movimentações espaço-corporais do narrador em viagem pelo Brasil, privilegiando sempre a deriva como método e os pensamentos triviais como partes da paisagem analisada:

O real se faz mesmo é de repetições, variações, simetrias, acasos, encontros e convergências que o que estão mesmo a pedir é decifrar-lhes continuidades e contigüidades. (CARVALHO, 2006: 15)

Como observador de segunda ordem, alguém que se observa em sua observação do mundo, o escritor parte de um acervo referencial, biográfico e simultaneamente literário, para converter a história em histórias. Este procedimento pressupõe um jogo deliberadamente dirigido ao leitor, afinal, como afirma:

o que há-de ser preciso escrever, em primeiro lugar, senão achar que vale a pena porque tem destinatário? E para contar uma estória, que outra única e suficiente razão poderá haver senão vontade de a contar, de contar coisas? (CARVALHO, 2006: 24) 
Da mesma forma, verifica-se no romance As paisagens propícias que a interrogação constante gerada pela obra corresponde, acima de tudo, a uma forma de levar o leitor a se questionar a respeito do seu "quintal metafísico" para basear a sua escrita no "labirinto pessoal de suas próprias derivas" (CARVALHO, 2006: 35):

Mas este, assim, será também o diário de quem? Do narrador, talvez sem dúvida, mas também daquele que tem o nome na entrada do livro. Qual dos dois se vai sentar aqui a pôr em ordem o que se segue, não só o diário daquilo que agora vier a ter interesse para o que quer contar, mas às voltas também com um caderno onde já antes registrou o que alguém que tinha coisas para revelar contou àquele que irá narrar-lhe a história agora, quer dizer... instauro o narrador e tomo nota... $\mathrm{E}$ a partir deste momento descubro-me a trabalhar, sem qualquer pejo, an nègre... (CARVALHO, 2005: 12)

O escritor parece assumir a multiplicidade de vozes na hibridez da escrita, problematizando os próprios limites referenciais da autoria. A renúncia a uma filiação literária ou antropológica estrita apresenta-se como um filtro na sua obra. Com isto, o não-privilégio de uma identificação constante permite verificar, em ambas as dimensões, a complexidade dos trânsitos culturais em que vivemos:

Mas depois de 1975 até ficava mal revelar apego ao Brasil, fazia parte do "passado colonial" (ainda hoje custa a lembrar esse papo multilusoracialtropicalista, de matriz brasileira, com que o colonialismo português nos andou a massacrar durante décadas), embora o Brasil dos coronéis tenha sido o primeiro governo do mundo a reconhecer a Angola independente e o seu governo, que se mantém até hoje no poder, ironias às vezes duplas e até triplas, que a história tece. E ainda assim... porque a Gabriela foi a primeira novela a ser emitida pela televisão angolana e o genérico da peça, novo rasgo de ironia, cantava essa música deliciosa que nos tratava a todos por camaradas e se enquadrava perfeitamente na nossa novel e militante cena nacional. (CARVALHO, 2006: 54-55)

Nessas crônicas do Brasil, o viajante costura pequenos pormenores a visões de mundo que passam por uma crítica ao uso da cultura brasileira como instrumento ideológico por parte do colonialismo português em Angola: 
E continuou-se a ouvir o rei Roberto Carlos e o samba sempre foi nosso também e nunca deixou de haver quem venerasse a voz de Elis Regina e depois fomos dando conta de como continuava a impor-se uma geração [...] a dizer coisas que se adaptavam perfeitamente a situações, a constrangimentos que para alguns de nós não havia maneira de não estar a ver que eram também cada vez mais os nossos, embora Angola estivesse a fazer uma revolução quando o Chico Buarque nos veio visitar numa de solidariedade internacionalista, pelo menos foi assim que se disse na altura, e arrancou essa glória que é a mulata de chocalho na canela, da Catumbela. (CARVALHO, 2006: 55)

O viajante que vem ao encontro do rio São Francisco abre, com a sua exploração cultural, um diálogo que transcende as paisagens e as questões literárias. Tomadas a partir de diferentes enfoques, as relações e os papéis desempenhados por brasileiros, portugueses e angolanos, no contexto póscolonial, são interrogadas a partir de suas especificidades culturais.

Do lado oriental da África, o moçambicano Mia Couto, ao apresentar uma palestra em homenagem a Jorge Amado, faz referência ao impacto da entrada de uma língua portuguesa específica que aportava, em Moçambique, sem a presença de Portugal:

Jorge não escrevia livros, ele escrevia um país. E não era apenas um autor que nos chegava. Era um Brasil todo inteiro que regressava a África. Havia, pois, uma outra nação que era longínqua mas não nos era exterior. E nós precisávamos desse Brasil como quem carece de um sonho que nunca antes soubéramos ter. Podia ser um Brasil tipificado e mistificado, mas era um espaço mágico onde nos renascíamos criadores de histórias e produtores de felicidade. Descobríamos essa nação num momento histórico em que nos faltava ser nação. O Brasil - tão cheio de África, tão cheio da nossa língua e da nossa religiosidade - nos entregava essa margem que nos faltava para sermos rio. ${ }^{1}$

Neste sentido, antes de concluir este artigo, é preciso que a perspectiva portuguesa seja destacada. Proponho evocarmos a perspectiva construída

1 Mia Couto, na conferência "Sonhar em casa", apresentada no SESC Pinheiros, em São Paulo, no dia 25 de março de 2008. 
por António Lobo Antunes, por exemplo, que, na sua ficção, produziu representações críticas sobre as relações luso-angolanas no contexto pós-colonial. Por uma perspectiva ainda mais diversa, o escritor focalizou o abandono do território africano pelas tropas portuguesas sem qualquer transição política e sem qualquer cooperação técnica e econômica, o que contribuiu para o agravamento da situação de miséria e de conflitos civis desencadeados nesses países, que encontravam apoio político e financiamento econômico na comunidade internacional para a manutenção do conflito civil. Esta focalização do autor está destacada em vários trechos de romances seus como As naus (1988), O esplendor de Portugal (1997) e Boa tarde às coisas aqui em baixo (2003).

Neles, lemos representações das conseqüências pós-revolucionárias tanto em Angola quanto em Portugal. Em sua obra, o fim da guerra colonial, o conflito civil na antiga África portuguesa e o retorno dos regressados são temas permanentes que propõem uma revisão do passado tradicional e o redimensionamento da ficção-império no contexto pós-revolucionário.

Lobo Antunes é um dos escritores que dá forma a uma obra ficcional e, com ela, propõe uma nova versão para o passado português, desnudando métodos e procedimentos menos gloriosos do que os que foram propagados ao longo do colonialismo, dando início a uma autognose portuguesa, nas palavras de Eduardo Lourenço, voltada para a investigação de "quem somos e o que somos como portugueses” (LOURENÇO, 2005: 84).

Para concluir, afirmo que há um campo na cultura lusófona que abre a possibilidade de se formularem relações e entendimentos - ainda que provisórios - acerca de uma perspectiva de conjunto, ou de uma perspectiva comunitária, como tem afirmado o pesquisador Benjamin Abdala Júnior. Esta proposta talvez inclua as noções de "ação recíproca" e de "comunhão de experiência histórica”, reclamadas no texto de Helena Riaúzova.

No conjunto de textos que esse campo é capaz de abarcar, verificam-se espaços e discursos múltiplos e possíveis sobre as histórias, as culturas, as variantes lingüísticas e as mitologias das diversas nações lusófonas. Esta proposta de estudo poderá contribuir para que as relações entre Portugal, Brasil e África sejam ativadas "em termos humanos e culturais e não apenas econômicos, sendo importante desenvolver cada vez mais um sistema de referências comuns para evitar silêncios e estranhamentos que, de momentâneos, se podem tornar permanentes" (ABDALA JUNIOR, 2003: 11). 
Neste sentido, tendo em vista que a noção de pós-colonialismo se radicou na atuação reflexiva e discursiva contemporânea, e, através da enorme bibliografia que lhe tem sido dedicada e de resultados de trabalhos já visíveis, se tornou um campo decisivo da nossa atividade de estudo, de pesquisa e de experiência cultural. Resta, entretanto, que seja examinada como uma noção fundamental a ser particularizada no âmbito das culturas de língua portuguesa e que se realize como um vigoroso desafio da literatura comparada.

\section{Referências Bibliográficas}

ABDALA Júnior, Benjamin. Apresentação: ensaios de relações e relações comunitárias. In: ABDALA JUNIOR, Benjamin (Org.). Incertas relações: Brasil e Portugal no século XX. São Paulo: SENAC, 2003.

CARVALHO, Ruy Duarte de. Desmedida: Luanda, São Paulo, São Francisco e volta. Crônicas do Brasil. Lisboa: Cotovia, 2006. - As paisagens propicias. Lisboa: Cotovia, 2005.

SANTOS, Boaventura de Sousa A gramática do tempo: para uma nova cultura política. Lisboa: Cortez, 1996.

LOURENÇO, Eduardo. O labirinto da Saudade. Lisboa: Gradiva, 2005.

Os girassóis do império. In: RIBEIRO, Margarida Calafate; FERREIRA, Ana Paula (Org.). Fantasmas e fantasias imperiais no imaginário português contemporâneo. Lisboa: Campo das Letras, 2007.

RIAÚZOVA, Helena. Dez anos de literatura angolana: ensaio sobre a moderna literatura angolana. Luanda: União dos Escritores Angolanos, 1986.

RIBEIRO, Margarida Calafate; FERREIRA, Ana Paula (Org.). Fantasmas e fantasias imperiais no imaginário português contemporâneo. Lisboa: Campo das Letras, 2007.

ROSA, Guimarães. Tutaméia. 7. ed. Rio de Janeiro: Nova Fronteira, 1985. 